\title{
Iri di Situs Jejaring Sosial: Studi tentang Teori Deservingness
}

\author{
Envy on Social Media: The Deservingness Theory of Emotion
}

\author{
Rani Armalita ${ }^{1} \mathcal{E}$ Avin Fadilla Helmi ${ }^{2}$ \\ 1,2Fakultas Psikologi Universitas Gadjah Mada
}

\begin{abstract}
This study examines the deservingness theory of envy over success stories post in the social media. The hypotheses are that there is a difference in; (1) the level of deservingness on posting stories of success gained through high effort (KUT) with success gained through low effort (KUR), (2) the level of envy over KUT and KUR posts, and (3) there is an influence of deservingness toward envy over KUT and KUR posts. A total of 214 undergraduate students became a subject of this research. The measurement of envy (y1) and deservingness (y2) over success post (x) used the scenario method. We used MANOVA-RM as the analysis technique to explore the envy and deservingness scores on KUT and KUR. MANCOVA-RM analysis was used to determine the effect of deservingness to envy. The findings suggest that envy increases when subjects are exposed to KUR post because of low deservingness.
\end{abstract}

Keywords: envy; deservingness; success post

Abstrak. Studi ini menguji teori deservingness mengenai iri terhadap postingan kesuksesan di situs jejaring sosial. Hipotesis penelitian ini adalah (1) terdapat perbedaan penilaian deservingness pada postingan kesuksesan pada usaha tinggi (KUT) dan kesuksesan usaha rendah (KUR), (2) terdapat perbedaan emosi iri pada postingan KUT dan KUR, dan (3) terdapat pengaruh penilaian deservingness terhadap iri pada postingan KUT dan KUR. Penelitian ini menggunakan metode skenario. Sebanyak 214 mahasiswa menjadi subjek penelitian. Pengukuran iri $\left(\mathrm{y}_{1}\right)$ dan penilaian deservingness $\left(\mathrm{y}_{2}\right)$ terhadap postingan kesuksesan ( $\mathrm{x}$ ) menggunakan metode skenario. Teknik analisis MANOVA-RM untuk melihat skor iri dan penilaian deservingness terhadap KUT dan KUR. Analisis MANCOVARM untuk melihat pengaruh penilaian deservingness terhadap iri. Hasil studi membuktikan hipotesis bahwa iri semakin meningkat ketika subjek melihat postingan KUR karena adanya penilaian deservingness yang rendah.

Kata kunci: iri; penilaian deservingness; postingan kesuksesan

Paradoks dari penggunaan situs jejaring sosial benar adanya. Suler (2004) memperkenalkan istilah disinhibition effect

\footnotetext{
${ }^{1}$ Korespondensi mengenai artikel ini dapat melalui: rani.armalita@mail.ugm.ac.id; ${ }^{2}$ avinpsi@ugm.ac.id
}

jejaring sosial yang menunjukkan bahwa komunikasi di jejaring sosial merupakan sebuah disinhibit atau sesuatu yang bebas 
dari hambatan, sehingga akan menimbulkan berbagai dampak.

Hal ini dapat dilihat dari dua fungsi jejaring sosial yang dikemukan Boyd dan Ellison (2007), yang menyatakan bahwa jejaring sosial dapat menjadi media komunikasi. Pertama, presentasi diri (menampilkan diri) baik itu secara real maupun virtual, dan dapat digunakan sebagai media berinteraksi, seperti mengobrol secara online berupa kiriman text maupun gambar, dan pada saat ini kecanggihan teknologi smartphone dapat berinteraksi melalui visual atau dikenal video call.

Beberapa penelitian menunjukkan sisi baik dari kegunaan jejaring sosial tersebut, yaitu bahwa fitur mengobrol dan presentasi diri dapat mengurangi kesepian (Aydin, Muyan \& Demir, 2012); meningkatkan dukungan sosial (Nabi, Prestin \& SoJ, 2013) serta menjadi sebuah media untuk mengungkapkan perasaan atau curahan hati (Andangsari, Gumilar \& Godwin, 2013). Dengan demikian, penemuan ini dapat dilihat sebagai disinhibition effect yang bermuatan positif. Artinya, ketika seseorang memiliki keterbatasan fisik untuk berkomunikasi (seperti malu, memilikikecemasan sosial), maka situs jejaring sosial menjadi suatu media yang dapat mengatasi keterbatasannya itu.

Namun di sisi lain, Boyd dan Ellison (2007) menyebutkan fungsi keduanya sebagai media untuk mendapatkan informasi tentang orang lain menunjukkan dampak buruk yang signifikan. Hal ini dibuktikan dari beberapa hasil penelitian terhadap aktivitas membaca postingan orang lain dapat menjadi media untuk melakukan perbandingan sosial yang tidak menyenangkan (Haferkamp \& Kramer, 2011; Chou \& Edge, 2012; Panger, 2014) dan bahayanya dapat menurunkan kesejahteraan psikologi pengguna (Burke, Marlow \& Lento, 2010).

Turunnya kesejahteraan psikologis seseorang dapat disebabkan oleh beberapa faktor pemicu. Hal ini dibuktikan oleh Krasnova, Wenniner, Widjaja dan Buxmann (2013) yang menemukan adanya reaksi emosi negatif berupa iri hati saat seseorang melihat postingan orang lain (berupa foto) yang berdampak pada menurunnya kepuasan hidup. Dalam temuan tersebut, iri ditemukan sebagai mediator antara penggunaan pasif (yaitu istilah untuk aktivitas melihat informasi saja di jejaring sosial) dan penurunan kepuasan hidup.

Hasil ini menunjukkan bahwa aktivitas memantau informasi tentang orang lain di jejaring sosial tidak secara langsung menurunkan kesejahteraan psikologis pengguna, namun didahului oleh reaksi emosional yang negatif yaitu emosi iri terhadap postingan orang tersebut. Inilah dampak disinhibit yang sarat akan hal negatif. Sehingga benar jika situs jejaring sosial memiliki paradoks yang nyata saat ini.

Belakangan terdapat beberapa studi yang juga mengkaji iri di situs jejaring sosial. Di antaranya adalah studi yang dilakukan Tandoc, Ferrucci, dan Duffy (2015) yang menemukan iri sebagai mediator antara penggunaan pasif dan depresi pada kalangan mahasiswa. Selain itu Bernarte, DelRosario, Pacho dan Raboy (2015) serta Lin dan Utz (2015) mengarahkan iri di jejaring sosial adalah sebagai perbandingan sosial. Sebelumnya, Festinger (1954) telah menyebutkan bahwa perbandingan sosial adalah suatu cara untuk mengukur kemampuan atau kualitas diri yang dilakukan seseorang terhadap kualitas orang lain. Namun demikian, Fiske (2013) menambahkan 
bahwa iri muncul karena adanya perbandingan sosial yang tidak menyenangkan karena melihat orang lain lebih baik atau sukses dibandingkan diri sendiri.

Laporan Pew Research Center (2014) memperlihatkan bahwa perkembangan dan pengguna jejaring sosial semakin meningkat. Kemudian saat ini setiap orang juga dapat memiliki lebih dari satu situs. Sebelumnya, Pew Research Center (2013) juga menemukan bahwa aktivitas paling populer di jejaring sosial saat ini adalah memposting foto. Terakhir, menurut data Asosiasi Penyedia Jaringan Internet Indonesia (APJII) pada tahun 2014, di Indonesia, aktivitas penggunaan situs jejaring sosial merupakan yang paling tinggi diantara aktivitas akses internet lainnya (APJII, 2014).

Iri, selain berdampak pada intrapersonal, juga merupakan permasalahan krusial dalam interaksi sosial (Faturochman, 2006). Hal ini dikarenakan iri merupakan keadaan mental atau intrapersonal yang dapat memengaruhi komunikasi interpersonal. Hal ini sejalan dengan pendapat Schoeck (1969) yang menyebutkan bahwa iri merupakan salah satu masalah fundamental yang terkait dengan relasi sosial. Bahkan Smith dan Kim (2007) menegaskan bahwa iri dapat menyebabkan konflik dalam hubungan interpersonal, termasuk konflik antar kelompok.

Relasi sosial di situs jejaring sosial saat ini memiliki potensi yang tinggi untuk menimbulkan dampak buruk terhadap intrapersonal maupun interpersonal melalui reaksi iri. Studi oleh $\mathrm{Hu}$, Manikonda, dan Khambampati (2014) tentang jejaring instagram menemukan adanya beragam konten foto yang dibagikan pengguna kepada sesama pengguna instagram, seperti yang diketahui bahwa instagram adalah media yang memberikan kesempatan pengguna untuk khusus memposting foto dan hasilnya. Dengan demikian inilah permasalahannya yaitu foto-foto yang menyenangkan diunggah orang lain, akan menimbulkan reaksi negatif dari seseorang yaitu merasa iri.

Iri sebagai suatu emosi bersifat cukup kompleks. Pertama, iri sering dinyatakan memiliki kemiripan dengan beberapa emosi lain seperti cemburu dan dengki. Namun demikian, ketiganya memiliki arti yang berbeda. Pertama, cemburu merupakan emosi yang terjadi ketika seseorang takut orang lain mengambil orang yang disayang (Smith, Parrot, Diener, Hoyle, \& Kim, 1999). Artinya, cemburu hanya dapat terjadi ketika terdapat tiga orang yang memiliki relasi. Sebaliknya, iri muncul saat ada dua orang yang berelasi, yang satu iri dan yang satu lagi diirikan (Faturochman, 2006). Kedua, iri dengan dengki merupakan reaksi emosi yang berbeda, iri bermuatan negatif atau emosi tidak menyenangkan yang dirasakan seseorang terhadap keadaan positif orang lain, sebaliknya dengki adalah reaksi emosional yang bermuatan positif atas keadaan negatif orang lain. Namun begitu, keduanya akan saling terkait, karena orang yang iri akan berpotensi memiliki dengki (Faturochman, 2006).

Permasalahan ini menunjukkan bahwa iri memperlihatkan dampak buruk yang semakin jelas. Hal ini mendorong penulis untuk melakukan penelitian terhadap permasalahan iri dalam konteks online atau di situs jejaring sosial. Terutama terkait dengan aktifitas melihat postingan orang lain. Tentu postingan yang dapat menimbulkan reaksi emosional yang negatif bukanlah postingan yang biasabiasa saja. Sebab iri pada seseorang tidak akan terjadi karena situasi orang lain yang biasa-biasa saja, tetapi akan terjadi karena 
situasi yang menyenangkan seperti meraih kesuksesan.

Kondisi seseorang yang sukses akan menjadi penilaian bagi orang lain yaitu penilaian terhadap kepantasan atas kesuksesannya (Feather, 1999). Hal ini dikenal dengan istilah penilaian deservingness (kepantasan). Teori ini berakar dari teori nilai oleh Frizt Heider yang menyebutkan bahwa umumnya orang lebih menyukai sesuatu yang konsisten antara usaha dan hasil pada seseorang. Berdasarkan hal tersebut teori deservingness menekankan bahwa tinggi rendahnya penilaian deservingness yang diberikan seseorang terhadap orang lain ditentukan oleh seberapa besar konsistensi atas usaha yang dilakukan dari kesuksesan yang diraih oleh orang tersebut (Feather, Mckee, \& Bekker,2011). Kebanyakan orang, akan lebih menyukai kesuksesan yang berbanding lurus dengan usaha yang dilakukan. Artinya penilaian deservingness akan tinggi terhadap kesuksesan atas usaha yang tinggi (KUT) pula, sebaliknya penilaian deservingness akan rendah saat kesuksesan tidak atas dasar usaha yang rendah (KUR).

Sebagai reaksi dari penilaian deservingness yang rendah tersebut maka muncullah emosi iri (Feather, 1999). Artinya iri terjadi saat seseorang menilai kesuksesan orang lain adalah sesuatu yang tidak pantas (penilaian deservingness rendah) karena melihat orang tersebut tidak melakukan usaha yang tingggi terhadap kesuksesan yang diraihnya, semata-mata hanya karena keberuntungan saja atau usaha yang sedikit saja. Reaksi iri seseorang terhadap kesuksesan akan berbanding terbalik dengan usaha orang tersebut atas kesuksesannya. Feather dan Sherman (2002) membuktikan bahwa saat kesuksesan merupakan hasil dari usaha yang tinggi (KUT) maka emosi iri akan semakin rendah, sebaliknya saat kesuksesan adalah disebabkan karena kurangnya usaha atau hanya melakukan usaha rendah (KUR) maka iri akan semakin tinggi. Hal ini sejalan dengan studi yang dilakukan Van de Ven, Zeelenberg dan Pieters (2012) yang juga menemukan bahwa iri diakibatkan oleh penilaian deservingness yang tinggi.

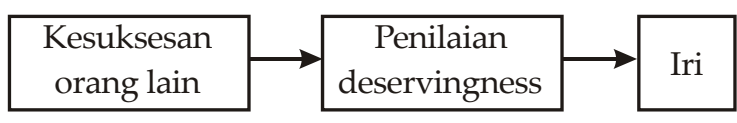

Gambar 1. Skema Terjadinya Iri yang Dilihat Berdasarkan Perspektif Deservingness oleh Feather (1999)

Penelitian ini menyajikan tiga hipotesis. Hipotesis 1, terdapat perbedaan penilaian deservingness pada postingan KUT dengan postingan KUR. Hipotesis 2, terdapat perbedaan emosi iri pada postingan KUT dengan postingan kesuksesan KUR. Hipotesis 3, Terdapat pengaruh penilaian deservingness terhadap iri pada postingan KUT serta penilaian deservingness terhadap iri pada postingan KUR.

Keterkaitan antara iri dengan penilaian deservingness tidak lepas dari konsep emosi yang dikemukakan Lazarus (1991) bahwa emosi sebagai dampak afektif terhadap proses kognitif (berupa penilaian) yang didahului oleh adanya stimulus dari luar. Konsep ini menekankan bahwa emosi merupakan sesuatu yang tidak dapat terpisah dari proses kognitif. Adanya keterkaitan antara penilaian (proses kognitif) dengan reaksi emosi, tidak lepas dari adanya beberapa emosi bersifat sosial yaitu emosi yang hanya akan terjadi jika terdapat faktor pemicu dari orang lain bukan faktor internal pada seseorang (Parkinson\& Manstead, 2015; Gross, 2015) dan biasanya tidak bersifat menetap. Dengan begitu, iri sebagai suatu emosi merupakan emosi yang bersifat state. 
Artinya, iri bukanlah sesuatu yang menetap pada diri seseorang melainkan adalah sesuatu yang bersifat situasional. Hal ini mirip dengan episodic envy yang dikemukakan oleh Cohen-Charash (2009) namun perbedaanya episodic envy tidak menguraikan proses kognitif yang terjadi saat iri berlangsung. Berbeda dengan konsep emosi yang dikemukakan Smith dan kawan-kawan (1999) yang menunjukkan iri adalah sebuah emosi yang bersifat dispositional, yaitu iri dianggap sebagai suatu emosi negatif yang bersifat menetap (trait) yang sudah menjadi sifat pada diri seseorang sehingga faktor situasional diabaikan atau tidak dianggap sebagai pemicu utama seseorang memunculkan iri.

Penelitian Krasnova et al. (2013) tentang iri di situs jejaring sosial terdahulu menggunakan konsep iri dari Smith dan kawan-kawan (1999). Demikian pula dengan studi-studi yang mengikutinya hingga tahun 2015. Belum ada yang mengaplikasikan konsep deservingness Feather (1999) untuk mengukur iri di situs jejaring sosial. Hal ini sangat kontra dengan penggunaan situs jejaring sosial yang notabene adalah suatu aktivitas. Artinya, iri tidak akan terjadi jika tidak menggunakan jejaring sosial, sehingga studi tentang iri masih dapat dikembangkan agar mampu menjelaskan bagaimana proses terjadinya emosi iri di situs jejaring sosial saat melihat postingan kesuksesan orang lain terkait dengan penilaian deservingness.

\section{Metode}

Subjek penelitian ini adalah mahasiswa Universitas Gadjah Mada program studi strata 1 (SI) dari Fakultas Psikologi, Pertanian, Kedokteran, Teknik, Ekonomi/ Bisnis, dan Farmasi, yaitu sebanyak 214 orang. Sebagian besar $(73,83 \%)$ berusia di atas 20 tahun $(\mathrm{N}=214)$ dan memiliki penilaian terhadap prestasi akademik yang cukup tinggi. Sebanyak 130 (60,74\%; $\mathrm{N}=214$ ) mahasiswa mempunyai IPK yang berkisar antara 2,75 hingga 3,45 dan hanya $7(3,27 \%)$ orang yang memiliki IPK di bawah skor 2,75.

Sebagian besar subjek aktif menggunakan Instagram (65,89\%) dan Facebook (61,21\%). Frekuensi penggunaan situs jejaring sosialpun sebagian besar atau $75,22 \%$ dari total subjek adalah 0-15 kali dengan durasi penggunaan dalam satu kali online rata-rata antara 1 jam hingga 2 jam yaitu sebanyak $74,76 \%$ atau 160 orang dari total subjek. Hanya 14,01\% subjek yang aktif untuk up date status sebanyak 2 hingga 5 kali per hari, selebihnya $(85,99 \%)$ hanya melakukan satu kali per hari.

Penelitian ini menggunakan metode skenario. Metode skenario umumnya dilakukan pada penelitian yang membutuhkan stimulus yang seragam untuk mengukur terutama penilaian

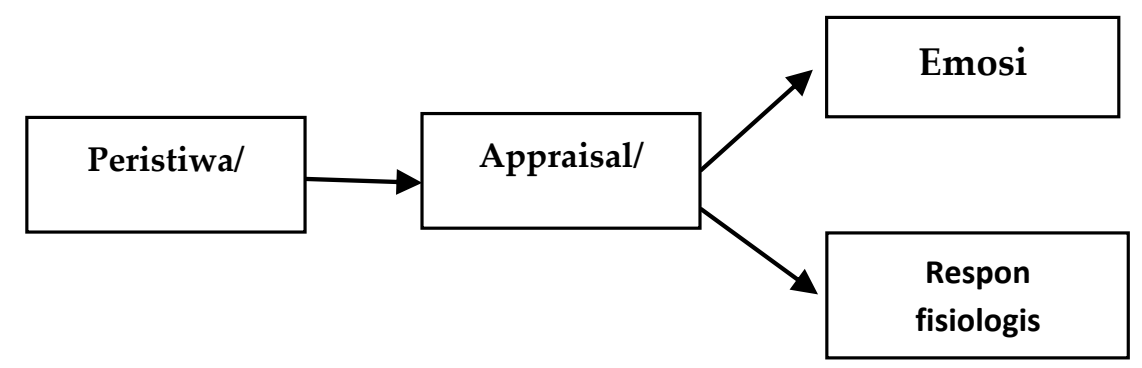

Gambar 2. Teori Emosi oleh Lazarus (1991) diadaptasi dari Buku "Emotions and Adaptation", oleh Richard Lazarus (1991). 
deservingness dan emosi yang dapat digeneralisasikan karena setiap orang memiliki penilaian dan emosi yang bersifat subjektif sehingga dibutuhkan stimulus yang dimanipulasi. Menurut Faturochman (2002) metode skenario memiliki kecanggihan yang mendekati penelitian eksperimen karena dapat memanipulasi variabel.

Pertimbangan peneliti menggunakan metode ini adalah variabel yang akan diukur adalah suatu kondisi psikologis yang umumnya bersifat subjektif pada seseorang, yaitu emosi. Iri merupakan emosi yang muncul karena faktor sosial, begitu juga dengan penilaian deservingness yaitu penilaian terhadap kesuksesan orang lain.

Untuk mengurangi bias dan generalisasi yang salah maka subjek penelitian akan diberikan stimulus atau manipulasi situasi yang sama setiap orangnya. Hal ini berarti variabel bebas (x) akan dimanipulasi.

Tabel 1

Kerangka skenario pengukuran iri di situs jejaring sosial

\begin{tabular}{ccc}
\hline & $\begin{array}{c}\text { Usaha } \\
\text { tinggi }\end{array}$ & $\begin{array}{c}\text { Usaha } \\
\text { rendah }\end{array}$ \\
\hline $\begin{array}{c}\text { Kesuksesan } \\
\text { (postingan foto } \\
\text { wisuda) }\end{array}$ & Skenario 1 & Skenario 2 \\
\hline
\end{tabular}

Prosedur penelitian. Skenario harus melalui proses validasi isi sebelum melakukan uji coba dan penelitian yang sesungguhnya. Validasi isi tersebut bertujuan menguji apakah isi telah sesuai dengan situasi yang ingin disajikan yaitu konteks postingan foto kesuksesan yang terdiri dari dua jenis usaha yaitu kesuksesan usaha tinggi (KUT) dan kesuksesan usaha rendah (KUR) atau tidak. Tim penilai yaitu 3 orang dosen Fakultas
Psikologi UGM yang memiliki keahlian terkait dengan metode skenario (dua orang dosen eksperimen) dan kajian situs jejaring sosial (satu orang dosen psikologi teknologi) dan beberapa orang mahasiswa pascasarjana program sains psikologi UGM.

Bersamaan dengan itu validasi isi juga dilakukan terhadap alat ukur iri (y1) dan penilaian deservingness (y2) yang berupa pertanyaan terhadap reaksi subjek skenario yang ditampilkan. Skala jawaban dari skala iri dan penilaian deservingness yaitu rentang nilai 1 hingga nilai 7 . Contohnya, 1) "seberapa kuat rasa tidak senang Anda terhadap cerita tersebut?" maka pilihan jawaban adalah mulai dari 1 (sangat tidak kuat) hingga skala 7 (sangat kuat).

Berikut daftar pertanyaan lengkap dari pengukuran iri dan penilaian deservingness pada postingan kesuksesan. 1) Seberapa kuat rasa tidak senang yang Anda rasakan saat melihat dan membaca postingan foto wisuda tersebut?; 2) Seberapa kuat rasa iri yang Anda rasakan saat melihat dan membaca postingan tersebut?; 3) Menurut Anda berapa nilai kelayakan predikat lulusan terbaik yang diraih tokoh?; 4) Berapa nilai kepantasan tokoh atas keberhasilannya meraih gelar terbaik sarjana?

\section{Cek manipulasi}

Tujuan cek manipulasi adalah melakukan pengecekan terhadap pemahaman subjek atas isi cerita skenario yang diberikan dan pemahaman subjek terhadap tata cara menjawab pertanyaan dalam skala ini. Dilakukan berupa pertanyaan setelah disajikan isi bacaan. Berikut kutipan skenarionya.

"Andi adalah seorang mahasiswa yang tekun belajar. Ia selalu mengerjakan tugas kuliah dengan sebaik-baiknya. Jika ada tugas kelompok, maka ia 
selalu berpartisipasi penuh untuk menyelesaikan tugas kelompok. Oleh sebab itu banyak teman-teman Andi yang senang bekerja sama dengan Andi dalam berbagai tugas kelompok. Di luar aktivitas kuliah, tak ketinggalan Andi juga memiliki segudang pengalaman akademik di luar kampus. Andi mengikuti beberapa kompetisi sains, seperti PKM ataupun karya ilmiah nasional maupun internasional, serta aktif mengirimkan tulisannya untuk konferensi-konferensi yang terkait dengan bidangnya. Dan tak jarang tulisannya diterima di berbagai konferensi nasional dan internasional. Pada hari ini Andi telah dinyatakan lulus sebagai seorang sarjana. Ia lulus dengan masa studi 3,5 tahun dengan IPK 3,9. Ia menjadi salah satu mahasiswa lulusan terbaik di kampusnya. Dan mengunggah foto wisuda di akun jejaring sosial miliknya".

Hendaknya dilakukan pengecekan ulang terhadap subjek, agar dapat melihat subjek membaca keseluruhan bacaan atau ada yang terlewatkan terutama untuk jawaban setiap pertanyaan. Jika dijawab benar berarti subjek dengan baik mengikuti semua instruksi.
Teknik analisis. Analisis yang digunakan terdiri dari dua. Pertama, pengukuran berulang multivariat (MANOVA Repeated Measured) untuk melihat perbedaan masing-masing skor iri pada KUT dan KUR serta skor deservingness pada KUT dan KUR. Kedua, teknik pengukuran Kovarian Multivariat (MANCOVA) untuk melihat apakah penilaian deservingness dapat menjadi kovarian atau berpengaruh terhadap tinggi rendahnya iri yang muncul dari postingan kesuksesan.

\begin{tabular}{lc}
$\mathrm{X} \rightarrow \mathrm{Y} 1 \rightarrow \mathrm{Y} 2$ & $\begin{array}{c}\text { (a) hipotesis pertama (MANOVA } \\
\text { Repeated Measure) }\end{array}$ \\
\hline $\mathrm{X} \rightarrow \mathrm{Y} 1$ & (b) hipotesis tambahan (MANCOVA \\
$\downarrow$ & Repeated Measure) \\
$\mathrm{Y} 2$ &
\end{tabular}

Gambar 3. Perkembangan Analisis Penelitian

\section{Hasil}

Terdapat perbedaan skor iri pada KUT dan KUR dan juga skor penilaian deservingness berdasarkan uji MANOVA RM. Denganskor rata-rata iri pada KUR $(7,79)$ lebih besar dibandingkan skor rata-rata iri pada $\operatorname{KUT}(6,70)$ dengan nilai $\mathrm{F}=117,502$ dan sig $p<0.000$. Sedangkan skor rata-rata penilaian deservingness pada KUT $(12,26)$ lebih tinggi dibandingkan $\operatorname{KUR}(7,02)$ dengan nilai $\mathrm{F}=178,442$ dan sig $p<0.000$.

Tabel 2.

Perbedaan rerataan iri dan penilaian deservingness pada postingan kesuksesan

\begin{tabular}{lcccccc}
\hline & \multicolumn{2}{c}{ Kesuksesan } & & F & Partial eta \\
\cline { 2 - 5 } & $\begin{array}{c}\text { Usaha tinggi } \\
\text { (UT) }\end{array}$ & $\begin{array}{c}\text { Usaha rendah } \\
\text { (UR) }\end{array}$ & Fquared \\
\hline Iri & 6,70 & 7,79 & $117,502^{* * *}$ & 1 &, 356 \\
Penilaian deservingness & 12,26 & 7,02 & $178,442^{* * *}$ & 1 &, 456 \\
Iri* & & & & & \\
\hline
\end{tabular}

Ket: ${ }^{*} p<.01 ;{ }^{* *} p<0.001 ;{ }^{* * *} p<0.0001$ 
Bahkan pada hasil uji coba sebelumnya rerataan iri dan penilaian deservingness pun juga menunjukkan perbedaan (lihat Tabel 3). Hal ini menunjukkan bahwa manipulasi KUT dan KUR dapat memprediksi perbedaan skor iri dan penilaian deservingness. Sehingga hipotesis 1 dan 2 dapat diterima.Hal ini disebabkan karena terdapat perbedaan yang signifikan pada masing-masing skor iri dan penilaian deservingness pada KUT dan KUR.

Sementara itu, uji MANOVA RM pada hasil ini juga menunjukkan bahwa terdapatnya interaksi antara iri dan penilaian deservingness $(F=272,324$; $p<0,000)$, didukung oleh besarnya nilai partial eta squared dari interaksi iri dan deservingness yaitu $56,1 \%$ (0.561) (lihat Tabel 2). Artinya skenario KUT dan KUR berkontribusi memengaruhi interaksi iri dan penilaian deservingness sebesar $56,1 \%$. Sebatas nilai tersebut belum dapat melihat pengaruh penilaian deservingness terhadap skor iri secara rinci. Maka analisis dilanjutkan dengan menggunakan MANCOVA RM agar dapat melihat masing-masing pengaruh penilaian deservingness terhadap iri (KUT \& KUR).

Hasilnya menunjukkan bahwa interaksi hanya terjadi pada postingan KUR yaitu skor penilaian deservingness dapat memengaruhi skor iri $(\mathrm{F}=7,622 ; p<0.00)$. Sedangkan pada postingan KUT tidak terlihat adanya pengaruh penilaian deservingness terhadap skor iri $(\mathrm{F}=2,649 ; p>0.1)$. Tabel 3

Perbedaan rerataan iri dan penilaian deservingness (sebelum \& sesudah penelitian)

\begin{tabular}{lllccccccc}
\hline \multirow{2}{*}{$\begin{array}{c}\text { Kelompok } \\
\text { manipulasi }\end{array}$} & \multirow{2}{*}{ Variabel terikat } & \multicolumn{4}{c}{ Uji coba* $^{*}$} & \multicolumn{4}{c}{ Penelitian } \\
\cline { 3 - 10 } & & min & maks & mean & SD & min & maks & mean & SD \\
\hline Kesuksesan Usaha & Iri & 2 & 14 & 6,74 & 2,885 & 2 & 14 & 6,70 & 2,882 \\
Tinggi (KUT) & Penilaian deservingness & 2 & 14 & 11,98 & 1,929 & & & 12,26 & 1,729 \\
Kesuksesan Usaha & Iri & 2 & 14 & 7,61 & 3,074 & 2 & 14 & 7,79 & 3,138 \\
Rendah (KUR) & Penilaian deservingness & 2 & 14 & 7,24 & 2,934 & 2 & 14 & 7,02 & 3,230 \\
*N=62 & & & & & & & & &
\end{tabular}

(Lihat Tabel 4). Berarti KUR tidak hanya memberikan perbedaan skor pada masingmasing iri dan penilaian deservingness (Hipotesis 1 \& 2 ) namun juga dapat menjadikan penilaian deservingness sebagai penentu tinggi rendahnya emosi iri ditunjukkan dengan nilai partial eta squared sebesar $0,035 \quad(3,5 \% ; \quad p<0.00)$. Sebaliknya pada manipulasi KUT, hanya dapat melihat perbedaan masing-masing skor iri dan penilaian deservingness, tidak terlalu berpengaruh memberikan peluang untuk penilaian deservingness menentukan tinggi rendahnya iri yang ditunjukkan dengan nilai partial eta squared yang rendah sebesar 0,012 dan nilai $p>0,1$. Hal ini menunjukkan pengaruh deservingness tidak signifikan yaitu $1,2 \%$ saja.

Hipotesis 3 diterima sebagian, yaitu terdapat pengaruh penilaian deservingness yang rendah secara signifikan terhadap skor iri yang tinggi pada KUR. Sebaliknya tidak terdapat pengaruh penilaian deservingness yang tinggi secara signifikan terhadap skor iri yang rendah pada KUT.

Tabel 4.

Analisis MANCOVA penilaian deservingness terhadap iri pada KUT dan KUR

\begin{tabular}{ccc}
\hline Analisis kovarian & F & $\begin{array}{c}\text { Partial eta } \\
\text { squared }\end{array}$ \\
\hline Iri* UT $^{*}$ & $2,649^{*}$ & 0,012 \\
Iri $^{*}$ UR & $7,622^{* *}$ & 0,035 \\
\hline
\end{tabular}

Ket: ${ }^{*} \mathrm{p}>0,01^{* *} \mathrm{p}<0.001$ 


\section{Diskusi}

Pertama, terbuktinya asumsi teori deservingness mengenai penilaian seseorang terhadap kesuksesan orang lain. Penilaian layak atau tidaknya (deservingness) akan dipengaruhi oleh seberapa besar usaha orang tersebut mengupayakan kesuksesannya. Hal ini dasarkan pada penekanan teori deservingness terhadap kontrol dari lokus, yaitu segala hal yang terjadi pada seseorang dianggap sebagai sebuah tanggungjawab diri sendiri, artinya sukses seseorang hanya dapat diterima jika ia berusaha untuk mencapai kesuksesan, jika tidak berusaha sebaik mungkin, maka kesuksesan yang ia peroleh adalah sesuatu yang tidak pantas ia dapatkan (Feather \& Sherman, 2002).

Terlihat dari perbedaan penilaian deservingness pada KUT dan KUR yaitu skor rata-rata penilaian deservingness KUT $(\bar{x}=12,26)$ lebih tinggi dibandingkan dengan nilai rata-rata penilaian deservingness KUR $(\bar{x}=7,02) \quad(\mathrm{F}=178,442 ;$ sig $p<0,000$ ).

Teori deservingness tentang emosi iri terhadap kesuksesan orang lain juga terbukti dalam penelitian ini. Hal ini tampak melalui adanya perbedaan skor rata-rata iri antara KUT $\left(\left(x^{-}=6,70\right)\right.$ dengan nilai rata-rata iri KUR $\left(\left(\mathrm{x}^{-}=7,79\right)\right.$ (nilai $\mathrm{F}$ sebesar 117,502 dan $p<0,000)$. Artinya, iri semakin tinggi saat melihat kesuksesan orang lain atas usaha yang rendah (KUR). Hal ini sejalan dengan pendapat Smith dan Kim (2007) yang menyebutkan bahwa usaha yang rendah atas sebuah keberhasilan yang diperoleh sering menimbulkan reaksi emosi yang negatif karena dianggap telah melakukan suatu yang curang dan tidak adil sehingga menimbulkan iri. Sebaliknya iri akan semakin rendah saat melihat kesuksesan orang lain adalah sesuatu yang diusahakan dengan baik (KUT).

Kedua, berdasarkan asumsi teori deservingness bahwa saat seseorang memberikan penilaian deservingness atau kelayakan terhadap kesuksesan orang lain maka dampaknya akan memunculkan reaksi emosi (Feather et al, 2011). Salah satu emosi yang dapat muncul terkait dengan penilaian deservingness adalah emosi iri. Asumsinya, iri semakin tinggi saat terjadi penilaian deservingness rendah terhadap kesuksesan yang berasal dari usaha rendah (KUR) dan iri semakin rendah saat terjadi penilaian deservingness tinggi terhadap kesuksesan yang berasal dari usaha tinggi (KUT). Uji hipotesis 3 menunjukkan gambaran dilapangan bahwa asumsi tentang pengaruh deservingness terhadap iri hanya terbukti secara signifikan pada situasi kesuksesan usaha rendah $(\mathrm{F}=7,622$; $p<0,01)$,

Dalam konteks penelitian, hasil menunjukkan skor iri yang tinggi karena memiliki penilaian deservingness yang rendah atau menilai tidak pantas terhadap postingan foto wisuda dengan cerita skenario yang tidak melakukan usaha apaapa selama masa kuliah (KUR). Dengan demikian, iri di situs jejaring sosial salah satunya disebabkan oleh munculnya penilaian deservingness yang rendah terhadap orang yang memposting foto kesuksesan, karena di kehidupan nyata terlihat bahwa kesuksesan yang ia pamerkan di situs jejaring sosial bukanlah karena usaha yang tinggi, namun usaha yang rendah.

Ketiga, penilaian deservingness yang tinggi tidak berpengaruh secara signifikan terhadap reaksi iri yang rendah pada skenario postingan KUT $(\mathrm{F}=2,649, p>0,01)$. Artinya, cerita KUT memang menimbulkan penilaian deservingness yang tinggi, namun tidak serta merta menurunkan skor iri. 
Apa yang terjadi? Hal ini dapat disebabkan berbagai alasan. Pertama, saat melihat kesuksesan yang berasal dari usaha tinggi, yang terjadi justru reaksi iri yang bermuatan positif. Arti iri dalam hal ini adalah ingin menjadi seperti orang tersebut yang sukses karena bekerja keras. Pendapat ini sejalan dengan penemuan dari Van de Ven, Zeelenberg, \& Pieters (2010) yang menemukan bahwa merasa iri terhadap prestasi orang lain yang dilakukan atas dasar usaha yang tinggi mampu menjadikannya sebuah kebanggaan, sehingga siapapun pasti ingin mengalami demikian. Kondisi yang demikianlah yang disebut iri positif. Kedua, pengaruh konten kesuksesan yang dipilih juga menjadi faktor yang memengaruhi, karena topik akademik seperti prestasi kuliah yaitu "lulusan terbaik" akan menimbulkan semacam iri namun untuk lebih giat agar dapat mencapai seperti kesuksesan orang lain. Faturochman (2006) menemukan bahwa banyak diantara mahasiswa yang merasa iri positif terhadap tema-tema prestasi akademik atau tema pengembangan diri.

Dengan demikian, untuk penelitian selanjutnya diharapkan agar tidak hanya melihat konsep iri yang negatif saja namun juga melihat iri sebagai emosi yang bermuatan positif saat melihat postingan kesuksesan terutama dalam konteks akademik.

Terakhir, mengenai metode skenario dalam penelitian ini, adalah kunci utama berlangsungnya penemuan-penemuan hasil teori deservingness terdahulu (Feather, 1999; Feather \& Sherman, 2002; Van de Ven et al., 2012) dan terbaru, dalam konteks situs jejaring sosial. Dengan metode ini, kondisi atau variabel bebas dapat direkayasa peneliti agar subjek memiliki kesamaan situasi sebagai landasan untuk mengukur penilaian deservingness dan iri senyata mungkin.

Salah satu keuntungan untuk melakukan metode skenario untuk mengukur kondisi emosional dan penilaian deservingness disebutkan Parkinson \& Manstead (2015) adalah bahwa posisi subjek bukan lagi sebagai seorang yang pasif dalam melaporkan kualitas emosi yang dirasakan pada situasi yang berbeda-beda, tetapi secara aktif juga ikut terlibat saat membaca skenario kemudian subjek dapat mengungkapkan respon emosional subjek yang dirasakan terhadap skenario yang diberikan.

\section{Kesimpulan}

Jika situasi usaha rendah yang menyebabkan kesuksesan, maka yang muncul adalah iri lebih tinggi dibandingkan pada situasi usaha tinggi yang menyebabkan kesuksesan. Sebaliknya, jika situasi usaha rendah yang menyebabkan kesuksesan maka yang muncul adalah penilaian deservingness yang rendah dibandingkan jika situasi usaha tinggi yang menyebabkan kesuksesan.

Terdapat keterkaitan antara penilaian deservingness dan iri yang muncul saat melihat kesuksesan orang lain yang disebabkan oleh usaha rendah, yaitu penilaian deservingness yang rendah menimbulkan emosi iri yang tinggi pada seseorang. Namun pada situasi kesuksesan orang lain karena usaha tinggi tidak menunjukkan adanya pengaruh penilaian deservingness yang tinggi terhadap munculnya iri.

Terakhir, teori deservingness terkait dengan penilaian deservingness dan emosi iri dapat diterapkan dalam konteks situs jejaring sosial melalui metode skenario. Karena deservingness dan iri yang sifat state sejalan dengan karakter situs jejaring 
sosial yang memang dasarnya adalah media yang dapat diakses kapan saja. Kapan saja seseorang dapat melihat postingan kesuksesan orang lain dan menimbulkan penilaian deservingness yang rendah dan iri yang tinggi dan hal ini dapat diukur melalui metode skenario.

\section{Saran}

Aktivitas melihat postingan foto kesuksesan ternyata memberikan dampak negatif pada pengguna yaitu emosi iri. Namun, dampak positif dari iri belum dapat dipastikan sehingga diharapkan bagi peneliti selanjutnya perlu dispesifikasikan konten emosi iri yang terjadi, apakah bermuatan positif atau negatif. Contohnya, dengan menambahkan kolom "alasan iri" setelah menanyakan "seberapa kuat rasa iri yang Anda rasakan". Selain itu, bagi peneliti selanjutnya juga diharapkan untuk dapat melakukan penelitian skenario dengan memperhatikan setting tempat penelitian. Seperti, menggunakan laboratorium komputer sehingga semua responden berada pada satu tempat agar dapat dikontrol dan cek manipulasi yang dilakukan dapat dipahami dengan jelas.

\section{Kepustakaan}

Andangsari, E. W., Gumilar, I., \& Godwin, R. (2013). Sosial networking sites use and psychological attachment need among Indonesia young adults population. International Journal of Sosial Science Studies, 1(2), 133-138. doi: 10.11114/ijsss.v1i2.66

Asosiasi Penyelenggara Jaringan Internet Indonesia. (2014). Profil pengguna internet di Indonesia 2014. Diakses dari www.apjii.or.id

Aydin, G. S., Muyan, M., \& Demir, A. (2012). The investigation of facebook usage purpose and shyness, loneliness. Sosial and Behavior Sciences, 93, 737-741.

Bernarte, R. P., Del Rosario, A. C., Pacho, P. J. M., \& Raboy, R. V. (2015). Hidden from your timeline: Facebook envy and self esteem of Filifino youth. European Academic Research, 3(1), 117-150.

Boyd, D., \& Ellison, N. B. (2007). Sosial network sites: Definition, history, and scholarship. Journal of ComputerMediated Communication, 13(1), 210-230. doi: 10.1111/j.1083-6101.2007.00393.x

Burke, M., Marlow, C., \& Lento, T. (2010). Sosial network activity and sosial wellbeing. CHI 2010, USA.Diakses melalui www.thoughtcrumbs.com/publications/bu rke_chi2010_sns_and_wellbeing.pdf

Chou, H-T.G., \& Edge, N. (2012). “They are happier and having better lives than I am": The impact of using facebook on perceptions of others's lives. Cyberpsychology, Behavior and Sosial Networking, 15(2), 171-121.

Cohen-Charash, Y. (2009). Episodic envy. Journal of Applied Sosial Psychology, 39(9), 2128-2173. doi: 10.1111/j.15591816.2009.00519.x

Faturochman. (2006). Iri dalam relasi sosial. Jurnal Psikologi, 33(1), 1-16. doi: 10.22146/jpsi.7082

Faturochman. (2002). Keterkaitan antara anteseden, penilaian keadilan prosedural, penilaian keadilan distributive, dan dampaknya (Disertasi tidak dipublikasikan). Yogyakarta: Universitas Gadjah Mada.

Feather, N. T., \& Sherman, R. (2002). Envy, resentment, schadenfreude, and sympathy: Reactions to deserved and undeserved achievment and subsequent failure. PSPB, (28)7, 935961. 
Feather, N. T. (1999). Judgments of deservingness: Study in the psychology of justice and achievement. Personality and Social Psychology Review, 3(2), 86-107.

Feather, N. T., McKee, I. R., \&Bekker, N. (2011). Deservingness and emotion: Testing a struktural model that relates discrete emotions to the perceived deservingness of positive or negative outcomes. Motive and Emotion, 35, 1-13. doi: 10.1007/s11031-011-9202-4

Festinger, L. (1954). A theory of sosial comparison processes. Human Relations, 7, 117- 140.

Fiske, S. T. (2013). Divided by status: Upward and downward scorn. Proceeding of the America Philosopical Society, 2013, USA.

Gross, J. J. (2015). Emotion regulation: Current status and future prospects. Psychological Inquiry, 26, 1-26.

Haferkamp, N., \& Kramer, N. C. (2011). Sosial comparison 2.0: Examining the effects of online profiles on sosialnetworking sites. Journal of Cyberpsychology, Behavior and Sosial Networking, 14(5), 309-314. doi: 10.1089/ cyber.2010.0120.

Hu, Y., Manikonda, L., \& Kambhampati, S. (2014). What we instagram: A first analysis of Instagram photo content and user types. In ICWSM 2014, USA. Diakses melalui rakaposhi.eas.asu.edu/ instagram-icwsm.pdf

Krasnova, H., Wenninger, H., Widjaja, T., \& Buxmann, P. (2013). Envy on facebook: A hidden threat to users' life satisfaction? Wirtschaftsinformatik, 92, 116.

Lazarus, R. S. (1991). Emotion $\mathcal{E}$ adaptation. Oxford University Press: NY.

Lin, R., \& Utz, S. (2015). The emotional responses of browsing facebook:
Happiness, envy, and the role of tie strength. Computer Human Behavior, 52, 29-38.

Nabi., R. L., Prestin, A., \& So, J. (2013). Facebook friends with (health) benefit?: Exploring the palliative effects of social network sites compared to interpersonal networks. Cyberpsychology, Behavior and Social networking, 16, 721-727. doi: 10.1089/cyber. 2012.0521

Panger, G. (2014) Sosial comparison in sosial media: A look at facebook and twitter. In CHI 2014 of a CHInd, Toronto, Canada.

Parkinson, B., \& Manstead, A.S. R. (2015). Current emotion research in social psychology: Thinking about emotions and other people. Emotion Review, 7(4), 371-380. doi: 10.1177/1754073915590 624

Pew Research Center (2014). Social media update 2014. Diakses melalui http://www.pewinternet.org

Pew Research Center (2013). Photo and video sharing grow online 2013. Diakses melalui www.pewresearchcenter.com

Schoeck, H. (1969). Envy. A Theory of sosial behavior. Liberty Fund: Indianapolis. Diakses melalui http://www. theaugeanstables.com/wp-content/ uploads/2013/02/schoeck-envy-1.pdf pada 28 Juni 2015.

Smith, R. H., \& Kim, S. H. (2007). Comprehending envy. Psychological Bulletin, 133(1), 46-64. doi: 10.1037/ 0033-2909.133.1.46

Smith, S. T., Parrot, W. G., Diener, E. F., Hoyle, R. H., \& Kim, S. H. (1999). Dispositional envy. PSPB, 25(8), 10071020. 


\section{ARMALITA \& HELMI}

Suler, J. (2004). The online disinhibition effect. Cyber Psychology \& Behavior, 7(3), 321-325.

Tandoc Jr, E. C., Ferrucci, P., \& Duffy, M. (2015). Facebook use, envy and depression among college students: Is facebooking depressing? Journal of Computers in Human Behavior, 43, 139146. doi: 10.1016/j.chb.2014.10.053

Van de Ven, N., Zeelenberg, M., \&Pieters, R. (2010). Warding off the evil eye:
When the fear of being envied increases prososial behavior. Psychological Science, 21(11), 1671-1677. doi: 10.1177/ 0956797610385352

Van de Ven, N., Zeelenberg, M., \&Pieters, R. (2012). Appraisal patterns of envy and related emotions. Motivation and Emotion, 36(2), 195-204. doi: 10.1007/ s11031-011-9235-8 